\title{
LATUX: An Iterative Workflow for Designing, Validating, and Deploying Learning Analytics Visualizations
}

\author{
Roberto Martinez-Maldonado \\ Connected Intelligence Centre, University of Technology Sydney, Australia \\ School of Information Technologies, The University of Sydney, Australia \\ roberto.martinez-maldonado@uts.edu.au
}

Abelardo Pardo

School of Electrical \& Information Engineering, The University of Sydney, Australia

Negin Mirriahi

School of Education \& Learning and Teaching Unit, University of New South Wales, Australia

\author{
Kalina Yacef \\ School of Information Technologies, The University of Sydney, Australia
}

Judy Kay

School of Information Technologies, The University of Sydney, Australia

\section{Andrew Clayphan}

School of Information Technologies, The University of Sydney, Australia

\begin{abstract}
Designing, validating, and deploying learning analytics tools for instructors or students is a challenge that requires techniques and methods from different disciplines, such as software engineering, human-computer interaction, computer graphics, educational design, and psychology. Whilst each has established its own design methodologies, we now need frameworks that meet the specific demands of the cross-disciplinary space defined by learning analytics are needed. In particular, LAK needs a systematic workflow for creating tools that truly underpin the learning experience. In this paper, we present a set of guiding principles and recommendations derived from the LATUX workflow. This is a five-stage workflow to design, validate, and deploy awareness interfaces in technology-enabled learning environment. LATUX is based on well-established design processes for creating, testing, and re-designing user interfaces. We extend existing approaches by integrating the pedagogical requirements needed to guide the design of learning analytics visualizations that can inform pedagogical decisions or intervention strategies. We illustrate LATUX in a case study of a classroom with collaborative activities. Finally, the paper proposes a research agenda to support designers and implementers of learning analytics interfaces. ${ }^{1}$
\end{abstract}

Keywords: Design, $\mathrm{HCl}$, groupware, visualizations, design, dashboard, awareness, software engineering

\footnotetext{
${ }^{1}$ An earlier, shorter version of this paper (Martinez-Maldonado et al., 2015) is the foundation for this article, which has been extended in light of feedback and insights from LAK' 15.
} 
(2015). LATUX: An iterative workflow for designing, validating, and deploying learning analytics visualizations. Journal of Learning Analytics, 2(3), 9-39. http://dx.doi.org/10.18608/jla.2015.23.3

\section{INTRODUCTION}

The field of learning analytics (LA) has emerged in recent years as a multidisciplinary research area with the aim of improving the overall learning experience for instructors and students. Several authors have highlighted the potential impact of this discipline to enhance teaching practice and student learning (Ferguson, 2012b; Siemens, 2012; Siemens \& Baker, 2012; Verbert et al., 2013) but at the same time, there is also a recognition of the importance of establishing a connection with other research fields such as the Learning Sciences (Siemens, 2012), Human-Computer Interaction (HCl) (Verbert et al., 2013), Information Visualization (Chatti, Dyckhoff, Schroeder, \& Thüs, 2012) and Computer Graphics (Duval, 2011). This is because the design of tools in this space demands challenging interdisciplinary processes (Balacheff \& Lund, 2013) in order to satisfy multiple goals and stakeholder requirements and to leverage the knowledge base of these different disciplines. There is substantial research demonstrating the value of LA (Ferguson, 2012b; Siemens \& Baker, 2012), describing the basic requirements for LA tools (Dyckhoff, Zielke, Bültmann, Chatti, \& Schroeder, 2012), envisioning the future of this field (Siemens, 2012), and providing general analytical solutions for specific contexts (Dyckhoff et al., 2012). However, little attention has been paid to exploring frameworks that can systematically help designers to develop, evaluate, and deploy effective LA tools. This is a critical time for learning analytics, because there is clear recognition of the need for effective interfaces but there are no standards yet. Our approach aims to facilitate the exploration of potential LA tools and to speed up the creation of validated tools for various purposes.

The area of Software Engineering (SE) provides established methodologies to help designers recognize processes, understand the requirements for interactive systems and iteratively evaluate these as they are built (Sommerville, 2011). The area of visualization and computer graphics also has established guidelines for designing general visual analytics interfaces (Thomas \& Cook, 2006). Similarly, the $\mathrm{HCl}$ and User Experience (UX) disciplines have a large array of methods for establishing user needs, and designing and evaluating interfaces (Hartson \& Pyla, 2012). However, these methodologies alone are not sufficient for building LA tools because they do not take account of the learning context. Dillenbourg et al. (2011) stated that traditional usability testing (mostly focused on individual or group interactions with computers) is not enough to prepare designs for the complexity of a learning context. The same authors suggested considering "usability at the classroom level." For example, in a classroom, instructors typically have to deal with multiple constraints and contingencies such as time limitations, curriculum alignment, lesson plans, physical space constraints, unexpected events, and tool usage. This complexity also occurs in blended and online learning settings (Prieto, Dlab, Gutiérrez, Abdulwahed, \& Balid, 2011) where LA tools are commonly used and potentially have a particularly valuable role. Similarly, Siemens (2012) proposed a holistic view of LA that includes such practical issues, but also aspects related to the data, such as openness, accessibility, and ethics, as well as the particular pedagogical goals and usage context of the LA tools (e.g., detecting at-risk students, supporting self-awareness, or enhancing instructor awareness). 
(2015). LATUX: An iterative workflow for designing, validating, and deploying learning analytics visualizations. Journal of Learning Analytics, 2(3), 9-39. http://dx.doi.org/10.18608/jla.2015.23.3

These complexities point to the need for new design methodologies for LA tools, providing a pedagogical underpinning and considering the different actors (e.g., instructors and students), the dimensions of usability in learning contexts (Dillenbourg et al., 2011) (individuals, groups of students, and the classroom), the learning goals, data sources, and the tasks to be accomplished. This paper presents LATUX (Learning Awareness Tools - User eXperience), a workflow for designing and deploying awareness tools for technology-enabled learning settings. By awareness tools, we refer to those that provide a user (instructor) with an enhanced level of awareness of what other actors (students) are doing in the learning space. The workflow extends well-established design approaches for developing user interfaces (UIs) by integrating the pedagogical requirements, collecting the relevant data from students, and evaluating the awareness tools. The evidence supporting the design of the LATUX workflow is illustrated with a case study of the iterative development of visualizations for in-classroom technology-enabled group activities to assist instructors in monitoring student collaboration and progress (Martinez-Maldonado, 2014).

The rest of the paper is organized as follows: The next section provides an overview of the current related LA methods followed by a brief description of the most relevant methods for interface development and evaluation used in SE and $\mathrm{HCl}$. Then, we define the LATUX workflow, with its four principles and five stages. The workflow is illustrated in the final section in terms of the iterations of design, evaluation, and the deployment of visualizations of student group activity in our case study.

\section{RELATED WORK}

\subsection{Awareness Tools: Visual Analytics, Learner Models and Dashboards}

There has been growing interest in the use of visual representations and interaction techniques that exploit the human perception to let instructors or institutional decision makers see, explore, and understand a varied range of sources of student data simultaneously (Duval et al., 2015; Kay \& Bull, 2015; Ritsos \& Roberts, 2014). This area has been called Visual Learning Analytics, making allusion to the more general field of Visual Analytics (Thomas \& Cook, 2006) that focuses on the provision of interactive, visual support for assessment, planning and decision making in general. Nevertheless, for the case of learning and teaching, a number of visual tools have been targeted to help teachers, learners, and other stakeholders gain awareness of, analyze, or reflect on relevant traces of the learning activity collected from the various learning spaces where students interact. These tools include, for example, Open Learner Models (OLMs), mostly targeted to students (Bull \& Kay, 2007), Academic Analytics, mainly focused at the institutional level (Campbell, DeBlois, \& Oblinger, 2007), scrutable group models (Upton \& Kay, 2009), or teacher's dashboards (Verbert et al., 2013). We can consider that these visual tools used in learning environments are different forms of learning analytics interfaces.

The need for a framework to analyze and identify effective visualizations is one of the key aspects that must be addressed to advance the field of learning analytics (Duval et al., 2015). The main issue is how 
(2015). LATUX: An iterative workflow for designing, validating, and deploying learning analytics visualizations. Journal of Learning Analytics, 2(3), 9-39. http://dx.doi.org/10.18608/jla.2015.23.3

to identify the real value of visualizations when used in real learning contexts, and the impact on the learning experience. The trade-off to consider is between the relevance of the data that might be presented and the manageable level of complexity for the stakeholders, in the context where they make use of the LA tool. For example, in visualizations provided to instructors to estimate academic risk, Ochoa (2015) identified the need to include a sense of the accuracy or source of uncertainty. These visualizations provide instructors with a nuanced description of the underlying results produced by the algorithms. What is the actual impact of including this information in a visualization? How are the instructors affected? These questions can be applied generically as in other visualizations, such as networks to represent short answers (Bakharia \& Dawson, 2015), visualization of tags previously collected by students in a learning environment (Niemann et al., 2015), networks of aggregated concepts derived from collaborative writing (Hecking \& Hoppe, 2015), or interactions captured in an interactive surface (Charleer, Klerkx, \& Duval, 2015).

The main challenge for creating such a framework is to make it generic enough to apply to the wide variety of possible visualizations, but still provide meaningful insight into the design process. The consequence of the lack of such formalism translates into a proliferation of visualizations exploring the limitations of what can be shown, instead of tackling the much-needed goals of relevance, usability, user satisfaction, and overall effectiveness. This paper aims to address this by providing a generic workflow targeted to support the design, validation and deployment of learning analytics interfaces.

\subsection{Learning Analytics Methods for Pedagogical Intervention}

Technology-enabled learning environments, whether online or face-to-face in the classroom, have the advantage of capturing copious amounts of data left in students' digital footprints (Duval, 2011; Greller \& Drachsler, 2012). When this data is made accessible to instructors, it can provide valuable evidencebased insights into student learning. Using data-mining techniques, the data captured from student interactions can be aggregated and analyzed by instructors to make better-informed pedagogical decisions. For example, data on student use of a Learning Management System (LMS) can reveal patterns of student engagement with certain tools (Beer, Jones, \& Clark, 2012; Macfadyen \& Dawson, 2010). However, these patterns are best understood by instructors when made available and visualized through user-friendly and intuitive LA tools. The challenge is to offer a low effort start-up for nontechnical users while offering additional functionality for more advanced users (Siemens, 2012).

The target audience for LA tools must be considered during the design process to ensure the insights gleaned from the data become actionable (Olmos \& Corrin, 2012). In the case of course-level analytics, visualization tools should highlight the intended learning goals identified by the instructor and whether these have been achieved (Gluga et al., 2013), or even allow instructors to apply the performance indicators appropriate for their learning context (Dyckhoff et al., 2012). The ability to observe whether students are engaging with a learning tool or progressing as intended allows instructors to identify when to intervene in order to support the students. This is especially challenging in online learning 
(2015). LATUX: An iterative workflow for designing, validating, and deploying learning analytics visualizations. Journal of Learning Analytics, 2(3), 9-39. http://dx.doi.org/10.18608/jla.2015.23.3

environments (Dyckhoff et al., 2012) and in large classes. For example, Social Networks Adapting Pedagogical Practice (SNAPP) represents student interactions within an online discussion forum to help instructors identify when to consult with students who are not engaging or when to change the nature of the activity (Lockyer, Heathcote, \& Dawson, 2013). Other learning analytics dashboards, such as Purdue University's Course Signals, provide data visualizations (traffic signals) to monitor performance and trigger early intervention when students may be at risk of poor performance or dropping out of a course (Arnold \& Pistilli, 2012). While there is no shortage of evidence to support the argument that LA tools to visualize student activity at the course-level are needed to inform instructors about their students' learning behaviour, there is limited research on effective workflows for designing such tools, particularly when focusing on data collected from face-to-face learning environments. This paper addresses this gap by proposing a design workflow that combines the rigour of $\mathrm{HCl}$ paradigms regarding user experience with a solid pedagogical underpinning.

\subsection{Designing User Interfaces}

Several methodologies have evolved over many years, to facilitate the process of software development and, specifically, user interface design. From a general SE perspective, these methodologies are commonly known as lifecycles (Sommerville, 2011) which, for example, may include waterfall, spiral development, prototyping, and extreme programming approaches. The purpose of the lifecycles in $\mathrm{HCl}$ is to help designers develop more efficiently and, for the case of user interfaces, to enhance the user experience. In other words, the lifecycles provide best practices for developers and designers.

The lifecycles in both $\mathrm{SE}$ and $\mathrm{HCl}$ disciplines have similar structures and activities. These include requirement identification, design, and evaluation. However, the methodologies for designing user interfaces in SE and $\mathrm{HCl}$ have been formulated almost independently (Hartson \& Pyla, 2012). There are a number of different $\mathrm{HCl}$ lifecycles, such as Mayhew's usability lifecycle, the Star lifecycle, the LUCID framework of interaction design, and the Wheel model (Hartson \& Pyla, 2012). The latter is a more recent elaboration of the iterative process model for usability engineering that provides a general framework into which designers can fit existing or new techniques or methods to apply "best user experience practices" (Helms, Arthur, Hix, \& Hartson, 2006). This is particularly relevant as a foundation for our LATUX workflow. Broadly, most of the lifecycles above have four generic stages (analysis, design, implementation, and evaluation) that should be performed iteratively, with potential for each stage to feed back to refine an earlier one. This iterative process for interface design can lead to a higher quality user experience.

Adding to the challenge for LA, Bevan (2009) argued for greater use of usability standards, but acknowledges that generic standards may fail to meet all the specialized needs of designers in specific areas (e.g., for LA tools design). A widely accepted standard relevant for developing interfaces for LA is the "Human-centred design for interactive systems" standard - ISO 9241-210 (2009). Its six principles are as follows: 1) the design should be based upon an explicit understanding of users, tasks, and 
(2015). LATUX: An iterative workflow for designing, validating, and deploying learning analytics visualizations. Journal of Learning Analytics, 2(3), 9-39. http://dx.doi.org/10.18608/jla.2015.23.3

environments; 2) users should be involved throughout the design; 3) the design should be driven by user-centred evaluation; 4) the process is iterative; 5) the design should address the whole user experience; and 6) the design team should be multidisciplinary in terms of skills and perspectives.

The LATUX workflow is based on this standard, and the evaluation-centred UX model (the Wheel) lifecycle concept (Hartson \& Pyla, 2012). Its novelty resides in the fact that it instantiates the user experience lifecycle with specific evaluation stages and requirements for designing awareness tools aimed at improving the learning experience, using data captured from students' activity with learning technologies.

\section{THE LATUX WORKFLOW}

The LATUX workflow is defined by 1 ) the principles on which it is grounded, and 2) the evaluationoriented stages that compose it (see Figure 1). The entire workflow is evaluation-oriented. Hence, each stage evaluates different parts of an awareness tool. The workflow has one problem identification stage and four evaluation stages. These principles and the stages are described in the rest of this section.

\subsection{LATUX Principles}

Based on LA literature and our first-hand experience, we identified a set of principles to take the workflow beyond generic development lifecycles. These principles are:

Principle 1: The development process in LA has a strong research component. In traditional software design, development is commonly based on iterative requirements elicitation. The classic UX approach involves exploring the design space and gaining feedback iteratively, with careful evaluation on each iteration. By contrast, developing effective awareness tools for learning settings also requires research to explore the new possibilities that learner data can offer to support instructors. As with every field that has been revolutionized by technology, LA tools can have a transformative role in education, in addition to improving its processes. Research needs to be carried out concurrently to understand how these changes can take place. At the current state-of-the-art, there is a prominent gap between research and practice in LA (Siemens, 2012) indicating the importance of this principle in the proposed workflow. This opportunity to close the gap is what Duval (2011) has highlighted as "Data-based Research on Learning."

Principle 2: The impact of authenticity; where the term authentic captures the nature of existing learning contexts without LA tools. In line with recognized UX practice, we need to distill the nature of learning contexts and how they impact the needs of each stakeholder and act as drivers for interface design. This aspect highlights the need to go beyond standard usability. Testing with a small number of users is a general method to evaluate interfaces and user experience. However, for awareness tools, the contingencies of real learning scenarios may affect and be crucial for the adoption of technology 
(2015). LATUX: An iterative workflow for designing, validating, and deploying learning analytics visualizations. Journal of Learning Analytics, 2(3), 9-39. http://dx.doi.org/10.18608/jla.2015.23.3

(Dillenbourg et al., 2011). As also noted by Rodríguez Triana, Martínez Monés, Asensio Pérez, \& Dimitriadis (2014), we need to align the design of the learning activities (tools usage, tasks, pedagogical strategies) and the learning analytics solutions to support instructors more effectively. In our workflow, each evaluation stage aims to increase the level of match between the awareness tool and the demands of authentic learning contexts, while moving towards the deployment of the tool in-the-wild (the classroom).

Principle 3: Holistic design and evaluation. In the same way that the LA field is multidisciplinary and focused on understanding systems as a whole (Siemens \& Baker, 2012), the design process to build LA tools must consider the complexity of learning environments. This includes the features of the learning tools, the adopted pedagogical approach, the physical space, the student social roles, etc. Additionally, the evaluation of the tools should also be holistic. For example, rather than evaluating the effectiveness of just the user interface of the awareness tool itself (in isolation), the evaluation should consider the tool in the context of the learning setting and its further impact on the actual learning-related activities - e.g., student retention, change in learning behaviour (Verbert et al., 2013), or instructor's attention (Martinez-Maldonado, 2014). This holistic view translates into a close relationship with Learning Sciences (Siemens \& Baker, 2012).

Principle 4: Evaluation is based on data and its meaningfulness. In addition to the evaluation of the UI, the design of LA tools has an additional dimension for evaluation; i.e., making sense of the student activity data or interpreting it in order to inform pedagogical decisions. A crucial part of the design and evaluation process includes the ways to distill data, present it, and validate it according to the pedagogical elements of learning and instruction (Knight, Buckingham Shum, \& Littleton, 2013) including representation, purpose, timing, context, learning goals, teaching goals, epistemic beliefs, and assessment approaches. For example, a specific data visualization may enlighten instructors when they reflect on student progress over the semester, but the same visualization may be useless in the classroom, or in other learning contexts. Thus, the design process should not only deal with questions about what data to present and how that data should be presented, but also where and how it will be used. While the evaluation in terms of usability and user experience still applies for LA tools, the workflow presented in this paper is not a software development or user experience lifecycle. This process incorporates and draws on the body of knowledge about learning contexts such as the learning cycle, where the students' learning activity or instruction is the focus of attention. Further, the design and evaluation of LA tools should be connected to both the context of the learning activity and the context of usage.

\subsection{LATUX Stages}

Figure 1 shows the conceptual representation of the stages featured in our proposed iterative workflow for designing and deploying awareness tools in the classroom. The problem definition is the first stage of 
(2015). LATUX: An iterative workflow for designing, validating, and deploying learning analytics visualizations. Journal of Learning Analytics, 2(3), 9-39. http://dx.doi.org/10.18608/jla.2015.23.3

recommended practice in $\mathrm{HCl}$ and $\mathrm{SE}$. The figure also shows the four evaluation-oriented stages that constitute the iterations towards deployment. The five stages are described below.

\subsubsection{Stage 1 - Problem identification}

Most literature presented above, concerning LA, has explored the different elements of the problem definition (Siemens, 2012; Siemens \& Baker, 2012; Verbert et al., 2013). The first stage aims to identify the requirements for LA and user interface design. This process offers an opportunity to identify possible new and radical features that can be offered by the data to address stakeholder needs, but where the stakeholders may not realize this. As noted under the first stage, Problem identification, in Figure 1, the first two questions to consider when identifying the LA-related problem concern the requirements and the unexplored possibilities that could be investigated. This can also lead to the consideration of multidisciplinary knowledge or expertise needed for the development of the learning analytics solution. For example, basic knowledge about information visualization is key when designing a dashboard; foundations of $\mathrm{HCl}$ can also be required to communicate learner's captured interactions to the instructors.

The third question concerns the identification of the stakeholders. Although LA has mostly focused on informing and empowering instructors and learners (Siemens \& Baker, 2012), Siemens (2012) identified other relevant stakeholders including faculties, departments, the whole institution, researchers, corporations, and government funders. From a SE perspective, stakeholder identification is a basic step for successful design (Sommerville, 2011). Hence, the design of LA tools should adopt this, carefully identifying the target stakeholders.

Once the stakeholders have been identified, the available data sources will need to be considered. According to Verbert et al. (2013), to date, research on LA has mostly focused on using student data linked to resource usage, interaction time, number of artefacts created, collaborative interactions, and task results. By contrast, assessing the impact of the data displayed in awareness tools has not been deeply explored. In addition, there are many additional data sources that can offer new insights into student learning (Blikstein, 2013), but these have been under-explored in the LA field. They include gesture sensing, wearable biosensors, head trackers, infrared imaging, depth imaging, and eye tracking. Even manual tracking of activity has not been widely used in LA (Verbert et al., 2013). As a continuation of the data source identification, Verbert et al. (2013) also indicated that the design of LA tools should include an analysis of the feasibility and trade-offs of considering alternative data sensors used to capture more complete student data. Currently, most LA solutions are based on application logs and forms of audio and video capture. The problem definition should include the analysis of the implications of introducing additional sensors in terms of the potential undesirable impact on the learning environment. Other elements of the problem definition addressed by LA research, as discussed below, are the following: stakeholder identification, data sources, types of data logging, features of the learning setting and design for evaluation. 
(2015). LATUX: An iterative workflow for designing, validating, and deploying learning analytics visualizations. Journal of Learning Analytics, 2(3), 9-39. http://dx.doi.org/10.18608/jla.2015.23.3

Alongside identification of the data sources, the learning and teaching approach or intended pedagogy should be considered. This is in line with the argument by Verbert et al. (2013) that there is a need for more research to identify the settings where particular LA approaches work well, and also to identify limitations and alternatives for learning environments where some LA solutions have been unsuccessful. This suggests a strong link between the development of LA tools and the context as a whole, and thus the risk of over-generalizing LA solutions. For example, the learning environment as well as the details of the learning context and tools deployed such as the activities and assessments, the student's prior experiences, technologies used, and intended learning outcomes should be considered in order to make sense of the data representing student activity and to make recommendations for other similar learning environments rather than over-generalizations.

Another key aspect to consider in an early stage of the design of awareness tools is the definition of the learner's rights, the student's data ownership, and ethical issues that can emerge and which can be specifically relevant for learning analytics (Ferguson, 2012a; Siemens, 2012). Slade and Prinsloo (2013) stated that it is important to understand both the opportunities and ethical challenges of learning analytics, which are socially and epistemologically shaped by the educational context and purpose of the awareness tools. Institutions, researchers, designers and/or practitioners must consider privacy and legal issues when defining the protocols for collecting, analyzing, interpreting, and storing student data (Bienkowski, Feng, \& Means, 2012). Some early actions can be taken to address possible ethical issues in

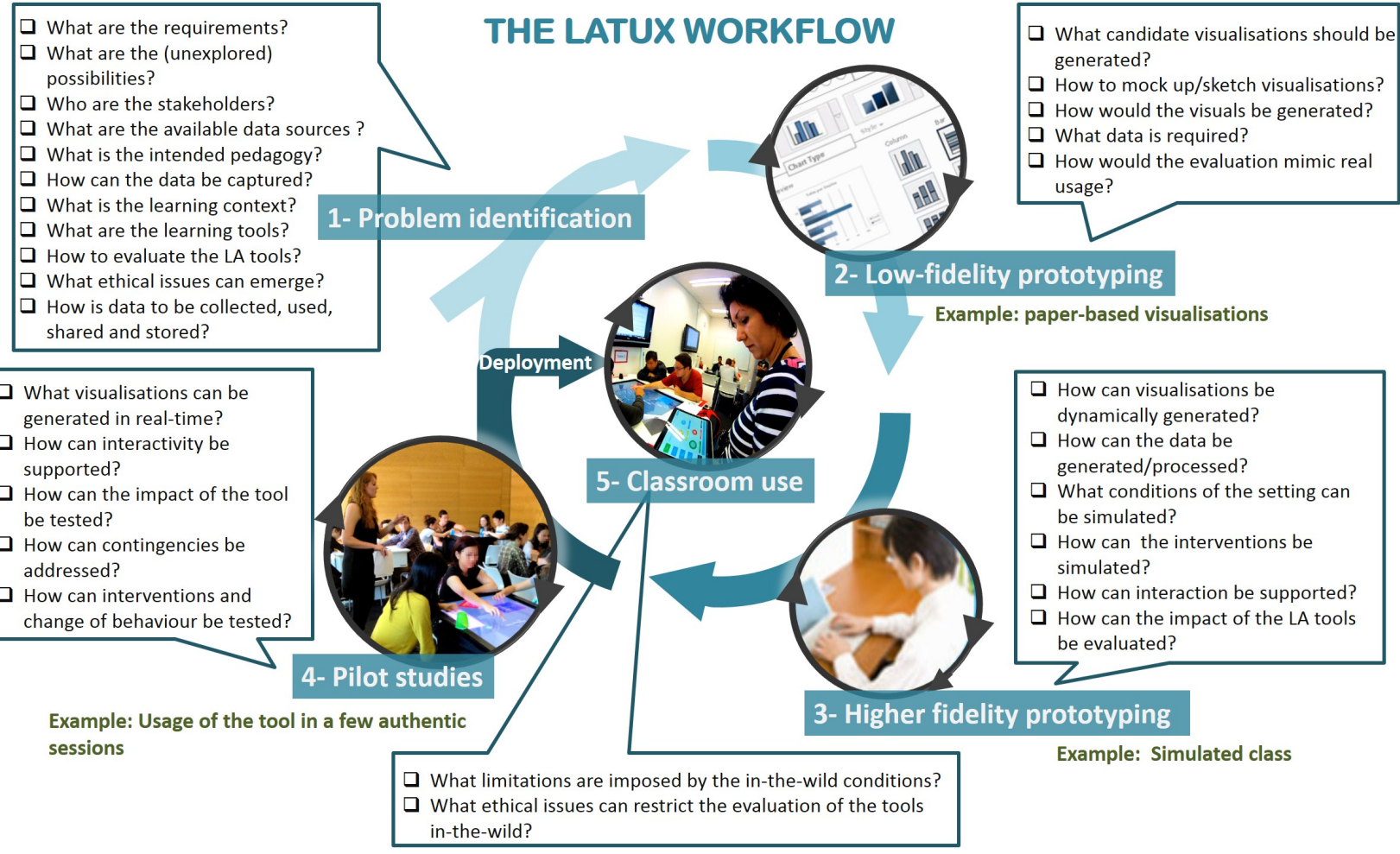

Figure 1. Conceptual Representation of the LATUX Workflow for Designing and Deploying Awareness Tools. Each stage features the guiding questions that designers can consider before or while designing and validating learning analytics visualizations. 
(2015). LATUX: An iterative workflow for designing, validating, and deploying learning analytics visualizations. Journal of Learning Analytics, 2(3), 9-39. http://dx.doi.org/10.18608/jla.2015.23.3

subsequent stages of the development. For example, policies can be defined for obtaining a student's consent to use their data (Slade \& Prinsloo, 2013). It can also be considered to agree on a data privacy statement or disclaimer. The de-identification of student data can also be required to accomplish specific purposes (e.g., for sharing data with third-party entities or for conducting research). All these concerns must be addressed within the constraints of national and broader privacy legislation. This broadly considers that the learners should be able to access their data and be in control of its uses. But the understanding of appropriate use of learning data is still evolving. Broad principles for ethical management of learning data in MOOCs were established at the Asilomar Convention for Learning Research in Higher Education in 2012. ${ }^{2}$ This aimed to facilitate progress in harnessing the potential power of the data, but at the same time respecting the learner's rights.

Finally, as the last question under Problem identification in Figure 1 shows, it is important to define how to evaluate the effectiveness of the use of LA tools in the target learning setting. This means designing the evaluation of the user experience according to the principles this workflow is grounded upon (e.g., considering the authenticity of the learning setting, meaningfulness, ethical concerns that can emerge in studies in-the-wild, etc.). Different measurement techniques should be used, as perception may not be an accurate way to evaluate the impact of a tool (Hartson \& Pyla, 2012). Measuring users' actions and the impact of such actions are also an indirect measure of the effectiveness of the learning analytics tool. These include usability testing, measuring the impact on teaching, learning gains, reduction in misconceptions, improved collaboration, enhanced instructor awareness, reduced load on the teacher, enhanced management of instructor time, etc. In addition, the conditions in which the evaluation will be performed (e.g., in the classroom, with simulated class conditions, simulated data, etc.) are required. Further details on this point will be discussed in the following stages of the LATUX workflow.

\subsubsection{Stage 2 - Low-fidelity prototyping}

The idea of prototyping in the early stages of development is to provide a quick and flexible preliminary vision of the proposed system (Hartson \& Pyla, 2012). To accomplish this, a prototype must contain some key elements of the system without actually building the system. Low-fidelity prototypes are initial, high-level representations of the intended design, which may be sketched or be illustrated using graphical wireframe tools. They are appropriate when the details of the tool have not been defined or are likely to change, so the construction of prototypes should involve little effort. In this stage, we propose the construction of low-fidelity prototypes for the purposes of: 1) testing a wide range of possible visualizations that can be part of the intended awareness tool; 2) testing usability and data sense making in the early stages of the design; and 3) evaluating and triggering dialogue with stakeholders before actually implementing the LA tool. To achieve these, Figure 1 lists a set of questions that may guide a designer in deciding: 1 ) how to generate and evaluate low-fidelity prototypes of awareness tools including the types of visualizations to be generated; 2 ) the strategies to be used to

\footnotetext{
2 http://asilomar-highered.info/
} 
(2015). LATUX: An iterative workflow for designing, validating, and deploying learning analytics visualizations. Journal of Learning Analytics, 2(3), 9-39. http://dx.doi.org/10.18608/jla.2015.23.3

initially illustrate and generate the visualizations; 3) the data required; and 4) how the evaluation strategy of the low-fidelity prototypes will strive to mimic the use of such visualizations in a real setting.

In LA, low-fidelity prototyping may focus on either the evaluation of the UI (user interface oriented prototype, e.g., a paper-based version of the interface where some visualizations can be drafted with simulated data) or the actual information conveyed in the visualizations (data-oriented prototypes, e.g., visualizations of data captured by the actual learning system or from shared datasets). The first case is closer to a typical $\mathrm{HCl}$ evaluation, while data-oriented prototyping is perhaps more relevant (and useful) in LA. We will provide an example of this in the Case Study described in the next section.

In either case, low-fidelity prototypes are commonly paper-based representations of parts of a system or tool. They are low cost and are highly effective to inform the design compared with higher-fidelity versions of the tool (Tohidi, Buxton, Baecker, \& Sellen, 2006) (see Table 1, column 1, first row). This is because one can readily create multiple prototypes, each exploring quite different approaches, and so gain insights into the relative strengths and weaknesses of each of them. This also enables participants in the evaluation studies to comment on them in comparative terms, without feeling the discomfort of being negative. They also allow evaluations with multiple users and under controlled lab conditions (e.g., it is easier to evaluate paper-based versions of a dashboard in one-hour interviews with multiple instructors than when the actual system is used).

By contrast, low-fidelity prototypes in LA have many limitations (see Table 1, column 1, row 2). They cannot replicate the connection between what occurs in an environment and the generation of data at that precise instant. In addition, these evaluations completely ignore the effect of interventions (e.g., instructors' actions or provision of feedback) or changes in student behaviour. They also afford very limited understanding of the user experience under authentic learning conditions (see Table 1, column 1 , rows 3 and 4). An alternative way to get rapid feedback in the initial stages of design is through the use of Wizard of Oz studies (Dahlbäck, Jönsson, \& Ahrenberg, 1993). In this method, an interface prototype looks as though it operates as intended, but actually lacks the backend to drive the full functionality and so a person must provide this.

\subsubsection{Stage 3 - Higher-fidelity prototyping}

The next stage in the workflow is to implement higher fidelity prototypes by creating at least a partial backend with meaningful data. From a $\mathrm{HCl}$ perspective, a high-fidelity prototype is a more detailed and realistic representation of the designed tool than a low-fidelity prototype (Hartson \& Pyla, 2012). It may include details of either the appearance or the interaction behaviour needed to evaluate how users interact with the tool or the data. High-fidelity prototypes require more effort and time, but the evaluation is still less expensive; these prototypes are faster to produce and more flexible than developing the final tool. 
(2015). LATUX: An iterative workflow for designing, validating, and deploying learning analytics visualizations. Journal of Learning Analytics, 2(3), 9-39. http://dx.doi.org/10.18608/jla.2015.23.3

For LA awareness tools specifically, we discuss the simulation and generation of student data and the conditions of the learning setting. This adds some degree of authenticity to the evaluation since the simulation may involve real student data and real-time usage. As indicated in Table 1 (first row, column 2), using simulation prototypes allows for the inclusion of a time factor and, therefore, the evaluation of the decision making process on the fly (e.g., it is possible to analyze what an instructor would decide to do, right after looking at the tool). Similar to low-fidelity prototypes, evaluations with more users can be performed under lab conditions compared with more authentic but costly pilot studies. In addition, some aspects of interaction design can be evaluated (e.g., analyzing how users would explore the data).

Experiments that are more complex can be designed to evaluate the user experience with a simulation tool since subjects can just focus on the details of the visualizations while the tasks can be replicated for multiple users in less time. However, as noted in Table 1 (second row, column 2), the impact of student or instructor actions are still ignored. Hence, the simulation of a tools' usage does not reflect what would actually happen in a real environment where students or the instructors can actively respond to the data presented via the awareness tool. Therefore, the effect of the tool on instructor or student actions cannot be tested. As a result, the designer should consider the trade-off between the low degree of authenticity with this type of prototyping and the effort needed to build it. Figure 1 presents some questions that can help the designer evaluate: 1 ) the ways visualizations can be dynamically generated; 2) how data can be generated and processed; 3 ) the conditions of the learning environment that can be simulated to evaluate the use of the visualizations within the awareness tool as authentically as possible; 4) how interventions can be simulated (e.g., the teacher speaking with students who may not be engaging with the tool as intended); 5) how such interactions can be supported; and finally, 6) how the impact of the tool can be evaluated without actually measuring learning or behavioural change.

Table 1. Strengths and limitations of the evaluation-oriented stages of the workflow.

\begin{tabular}{|c|c|c|c|c|}
\hline \multirow{3}{*}{ Strengths } & $\begin{array}{l}\text { Low-fidelity } \\
\text { prototyping }\end{array}$ & $\begin{array}{l}\text { Higher-fidelity } \\
\text { prototyping }\end{array}$ & Pilot studies & Validation in-the-wild \\
\hline & \multirow[t]{2}{*}{$\begin{array}{l}\text {-Testing usability and } \\
\text { sense making in early } \\
\text { stages } \\
\text {-Testing with multiple } \\
\text { people } \\
\text {-Very cheap }\end{array}$} & \multirow{2}{*}{$\begin{array}{l}\text {-Simulated decision making } \\
\text { on the fly } \\
\text {-Testing with multiple } \\
\text { people } \\
\text {-Deeper evaluation by } \\
\text { users } \\
\text {-Interactivity can be tested } \\
\text {-Cheap }\end{array}$} & \multicolumn{2}{|c|}{$\begin{array}{l}\text {-Authentic-live usage of the tool } \\
\text {-Interactivity can be tested } \\
\text {-Interventions affect the use of the tool } \\
\text {-Impact of the tool on users' can be tested } \\
\text {-Contingencies considered }\end{array}$} \\
\hline & & & -Cheaper than full deployment & $\begin{array}{l}\text {-More generalisable } \\
\text {-Testing with multiple people } \\
\text {-Reduced 'novelty-effect' }\end{array}$ \\
\hline Limitations & $\begin{array}{l}\text { - Time factor missing } \\
\text {-Interventions cannot } \\
\text { be tested } \\
\text {-Interactivity cannot be } \\
\text { easily tested }\end{array}$ & $\begin{array}{l}\text {-Interventions cannot be } \\
\text { tested } \\
\text {-More expensive than } \\
\text { static prototypes }\end{array}$ & $\begin{array}{l}\text {-More expensive than } \\
\text { prototyping } \\
\text { - Testing with fewer people } \\
\text { - Less generalisable }\end{array}$ & $\begin{array}{l}\text { - The most expensive } \\
\text { - Contingencies } \\
\text { - Limited experimental } \\
\text { conditions }\end{array}$ \\
\hline \multicolumn{5}{|l|}{$\begin{array}{l}\text { Controlled } \\
\text { conditions }\end{array}$} \\
\hline Authenticity & & & & \\
\hline
\end{tabular}


(2015). LATUX: An iterative workflow for designing, validating, and deploying learning analytics visualizations. Journal of Learning Analytics, 2(3), 9-39. http://dx.doi.org/10.18608/jla.2015.23.3

\subsubsection{Stage 4 - Pilot studies: Classroom use}

The fourth proposed stage before deploying an awareness tool in-the-wild is the evaluation of the user experience in pilot studies. A pilot study is commonly accomplished under conditions similar to a real deployment but on a smaller scale (e.g., in a limited number of classroom sessions or during a limited period in a course). A pilot study can help prove a concept and observe the live usage of the tool in an authentic context. This is recommended as part of the design workflow to minimize the risk of deploying an LA tool on a large scale while there is still a need for more research and evaluation.

Key new knowledge can be gained from pilot studies including testing interactivity. This can include the analysis of the impact of the interventions and change of behaviours because of using the tool. In pilot studies, it is also possible to test the effect of the tool and the unexpected events that may occur on learning and instruction (see Table 1, column 3, first row). Figure 1 provides five questions that should be considered when designing a pilot study: 1) the types of visualizations that can be generated in realtime (e.g., to be used when the teacher wants to whether during the class or external); 2) how interactivity with the awareness tool would be supported during the pilot; 3) strategies for testing or evaluating the impact of the tool; 4) how contingencies will be addressed, and 5) how teacher interventions or changes in student behaviour will be tested or evaluated.

However, pilot studies are typically more expensive in terms of effort and coordination, compared with evaluating low- or high-fidelity prototypes in the lab (Hartson \& Pyla, 2012). Added to that, results obtained from pilot studies are not necessarily generalizable. Setting controlled variables can be restrictive; depending on how authentic the learning conditions are (e.g., pilot studies in real schools may impose limitations on the range of items that can be evaluated). In addition, the amount of evidence and subjects can be more limited than performing shorter but more numerous evaluations with prototypes under lab conditions (see limitations in Table 1, column 3, second row).

\subsubsection{Stage 5 - Validation in-the-wild: Classroom use}

Evaluating in-the-wild has become a standard method within $\mathrm{HCl}$ testing (Brown, Reeves, \& Sherwood, 2011). In-the-wild testing consists of field trials of experimental systems with groups of subjects in relatively unconstrained settings outside of the laboratory, at a larger scale and for a longer duration than in pilot studies. For LA research and practice, this can help designers recognize the actual deployments as another evaluation stage of user experience. Similar to a pilot study, deployments inthe-wild provide an authentic test-bed to analyze not only usability and user experience, but also the usage and the impact of awareness tools in an unpredictable learning environment and within the context of the pedagogical requirements and goals (see Table 1, column 3, first row).

The actual use of the awareness tool can be tested, considering the possible contingencies that may occur. As the authenticity of the setting is higher and the duration of the study can be longer than a pilot study, the results of the evaluation of the awareness tool may be more generalizable to real world contexts and use. In addition, the longer-term usage of an awareness tool can minimize the "novelty- 
(2015). LATUX: An iterative workflow for designing, validating, and deploying learning analytics visualizations. Journal of Learning Analytics, 2(3), 9-39. http://dx.doi.org/10.18608/jla.2015.23.3

effect" inherent in introducing new technology. This effect cannot be easily analyzed in smaller pilot studies or in prototype testing. This aspect is important for designing and testing LA tools since the ultimate goal of a successful deployment is the sustained usage of the tool for its intended learning or teaching goal.

In addition, testing the tool in-the-wild may require more challenging learning management, ethical and privacy issues to be addressed given the larger scale use of the tools compared with pilot studies (Table 1 , column 3, second row). These aspects may influence the design of an awareness tool and inform the two key questions the designer should consider prior to deploying an awareness tool as noted in Figure 1. Namely, the designer should consider the limitations posed by "in-the-wild" conditions (e.g., class size producing a larger data set, technological infrastructure or lack thereof, and the extent of teachers' data literacy to be able to make sense of the visualizations represented) and any particular ethical issues emerging from the evaluation of the tool in-the-wild. We include this consideration at this stage, in addition to the first stage's planning, because the earlier stages work towards a tool that can be used in multiple classes of envisaged settings. When it comes to testing in a particular class and context, the pragmatics of each will need to be considered.

Finally, evaluating LA tools in authentic deployments is the most expensive stage in a design workflow. They may also be more restricted to fit the context. Testing under authentic conditions can also affect the use of the tool and the evaluation. Typically, they offer less flexibility and this means that one cannot ensure the systematic testing of a broad coverage of diverse cases. By contrast, a lab setting makes it possible to ask the users to work through a carefully designed and comprehensive set of artificial tasks (Table 1 , column 4 , second row).

\subsubsection{Iterative Design-Deployment-Evaluation}

Finally, bridging the gap between practice and research calls for communication of what happens in the deployment to inform the possible tuning or re-design of the tools. This invites the definition of iterations of design either to develop the LA tools in small incremental steps, or to improve certain elements of the UI or data processing. Mendiburo, Sulcer, and Hasselbring (2014) highlights the importance of iterative interaction design to generate their LA tool, but other than this example, iterative design in LA has not been explored and reported in depth. The designer may want to respond to some questions once the system, or part of it, has already been deployed, such as what evaluation stages may be needed in an iteration (e.g., some functionality of the awareness tool may not require all stages of prototype testing or pilot studies)? What is the goal of the current iteration? What knowledge should be gained from a research perspective? How many iterations are required? As shown in Table 1 (rows 3 and 4), each stage within an iteration of the proposed workflow features a trade-off between the authenticity and degree of control of the learning setting conditions. 
(2015). LATUX: An iterative workflow for designing, validating, and deploying learning analytics visualizations. Journal of Learning Analytics, 2(3), 9-39. http://dx.doi.org/10.18608/jla.2015.23.3

\section{CASE STUDY}

We illustrate our workflow by describing the iterative development of the MTDashboard (MartinezMaldonado, Dimitriadis, Kay, Yacef, \& Edbauer, 2013). This interactive dashboard was designed for a teacher in a multi-tabletop classroom. It aimed to help the teacher manage the multiple devices in the technology-enhanced environment and gain understanding of the students' collaboration and task progress. The dashboard proved effective in enhancing instructor awareness and in helping them decide how to direct the time and attention of students by providing informed feedback in a number of higher education classroom studies in classes with more than 500 students.

\subsection{Stage 1 - Problem Identification}

We describe the context of the work in terms of the problem definition as a starting point of our design workflow. The objective of the project is to design, evaluate, and deploy a number of visualizations of student group work in a classroom. The purpose of this is to enhance instructor awareness of students' small-group collaboration and task progress. The group activity was supported either in the lab or in the classroom using interactive tabletops. These shared multi-touch devices enable small groups of students to work on a learning task where they manipulate digital media while communicating face-to-face. Figure 2 (left) shows three students working on such a collaborative activity. The main requirement, from the LA point of view, was to generate an awareness tool (like the one shown in Figure 2, right) in the form of an instructor dashboard to monitor student collaboration and group progress on the learning activity while the students worked in small groups using multiple tabletops.

Data sources and Data logging. Three main sources of student data were identified for the project: the physical manipulation of virtual objects on the tabletop, quantitative dimensions of student speech (e.g., presence and duration of utterances), and students' task progress (e.g., measures of the quality of the learning artefacts produced). Regarding the tabletop technology, there has been little research on sensing technology to capture the above types of student data automatically in face-to-face learning settings. Part of the project included the production of the technology to recognize user-differentiated touches on the tabletops automatically and to synchronize those with the detection of audio activity by the learners at the table. The sensing system CollAid was developed to capture datasets of students' activity at an interactive tabletop, to provide fine-grained data about learner activity similar to that currently collected in online learning environments. It records the timestamp of each action performed by each student on the multi-touch learning application. CollAid can also determine which student is speaking at any time. So it captures the duration of each student utterance and whether such verbal participation followed another student speaking. More information about how the speech and touch activity can be automatically captured in tabletop-based face-to-face settings can be found in MartinezMaldonado, Collins, Kay, and Yacef (2011). An analysis of the accuracy of the vision-based system that CollAid uses to identify touches indicated that it was highly accurate for normal use by students; details of which can be found in Clayphan, Martinez-Maldonado, Ackad, and Kay (2013). 
(2015). LATUX: An iterative workflow for designing, validating, and deploying learning analytics visualizations. Journal of Learning Analytics, 2(3), 9-39. http://dx.doi.org/10.18608/jla.2015.23.3

Features of the learning setting. For the prototyping stages and pilot studies, the learning activity involved the construction of a concept map to tackle problem solving and case-based resolution tasks collaboratively. Collaborative concept mapping is representative of a group learning activity that requires students to share their perspectives, visually represent their ideas, and agree on a group solution (Chaka, 2010). For the collaborative tasks at the tabletop, students used the multi-touch concept map editor CMate (Martinez-Maldonado, Kay, \& Yacef, 2010). For the in-the-wild deployment, two additional learning applications were used: 1) ScriptStorm, a brainstorming application (Clayphan, Kay, \& Weinberger, 2013); and 2) WellMet, a tool for supporting project management meetings. Additional details about the features of these tools can be found in Martinez-Maldonado, Clayphan, Ackad, and Kay (2014).

Evaluation. In this project, classroom instructors were the main stakeholders and source of requirements for the tool. Therefore, their role was crucial in the evaluations discussed below. Additionally, a number of research goals were set for the project to explore various visual analytics tools and their effectiveness in conveying information about students. Thus, additional required sources were identified by reviewing relevant research literature.

\subsection{Series of Studies}

The design process in the case study included the following series of smaller studies, which support Stages 2 to 5 respectively of the LATUX workflow. The first explored a wide range of candidate visualizations based on paper prototypes (Martinez-Maldonado, Kay, \& Yacef, 2011). The second consisted of trials in the lab, with teachers analyzing real student data, but simulating classroom sessions (Martinez-Maldonado, Yacef, Kay, \& Schwendimann, 2012). The third included two pilot studies in real classrooms conducted in two different semesters (Martinez-Maldonado et al., 2013). The fourth was a longitudinal classroom experience with four instructors delivering two one-semester courses (Martinez-Maldonado et al., 2014).

\subsubsection{Stage 2 - Validation of prototypes}

Description of the study: The first study focused on exploring visualizations of small-group face-to-face work that could be generated from the data captured from a tabletop device in a lab setting such as the one shown in Figure 2 (left). The learning task had two stages: first, an individual stage, where each group member created their own concept map; and then, a group stage, where they came together to create a shared map using the CMate tabletop tool. The data for the study was collected for 10 participants in three groups, each with three or four participants. Drawing on previous work on social proxies (Erickson et al., 1999), equity of oral participation and decision making (Bachour, Kaplan, \& Dillenbourg, 2010), and levels of participation at the tabletop (Harris et al., 2009), four visualizations were generated. This initial set of visualizations was designed to provide key indicators of accountability of student contributions to the group solution, the progress of the task, and how egalitarian the activity 
(2015). LATUX: An iterative workflow for designing, validating, and deploying learning analytics visualizations. Journal of Learning Analytics, 2(3), 9-39. http://dx.doi.org/10.18608/jla.2015.23.3

was amongst learners. The visualizations were generated using a computer-drawing editor. Details of these visualizations can be found in Martinez-Maldonado, Kay, and Yacef (2011). Two sets of the visualizations were printed on paper (see Figure 2, right). These sets were generated based on real data obtained from the video recordings of two selected groups of three students each collaborating at the tabletop on the concept mapping task.

Evaluation: We illustrate a way to evaluate candidate visualizations in early stages of design using real student data by describing the evaluation of the paper-prototypes described above. The usability and meaningfulness of the visualizations were both tested using the prototypes. Regarding usability, an instrument was first applied to investigate if all the instructors were able to understand the visualizations. Then, a second instrument tested a series of hypotheses that questioned if the set of visualizations revealed key facets of the group collaboration processes to the instructors. These were about equity and amount of participation, overall collaboration, equity of intellectual contribution, and the creation process. In order to assess whether the visualizations conveyed enough information about group work, we ran evaluation sessions with five skilled instructors, each with experience in orchestrating classroom group work. We provided each instructor with a set of the visualizations generated from the tabletop sessions of two groups: A and B. We also provided the final maps, from both the individual and collaborative stages. Then, we invited the instructors to respond to a set of questions about the equity of participation, quantity of participation, the collaboration, the equity of intellectual contribution of the group members, and the usefulness of the visualizations to depict the creation map process in terms of contribution and group work. We asked the instructors to think-aloud while inspecting the visualizations, explain their responses, and state which visualizations they used or if the visualizations did not give enough support for making a decision. As a basis to compare the information inferred by the instructors from the visualizations, the video recordings of each group's session were analyzed so they could be used to compare against the instructor's thinking process. The instructors neither watched the videos nor had access to summaries of what actually happened during
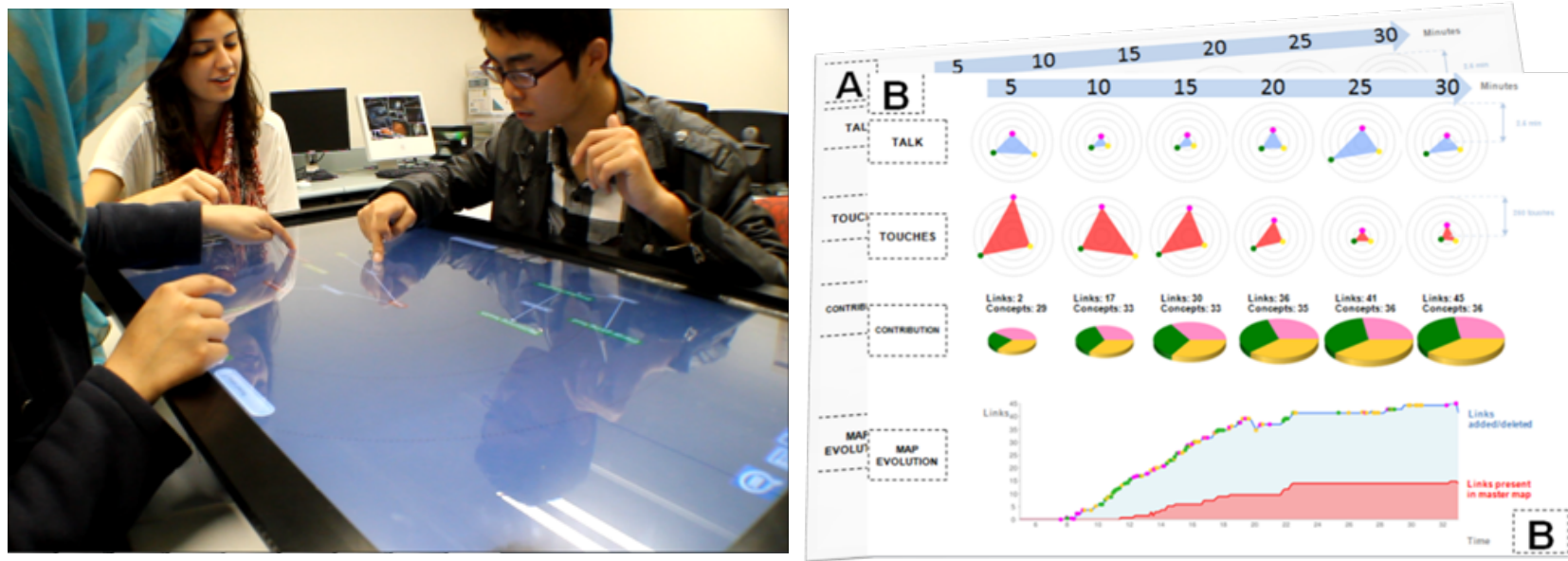

Figure 2. Case-study learning environment: Left: a three-member group acomplishing a collaborative learning task in the lab; Right: Example of a paper-based prototype for validating visualizations with each row showing the next visualizations: 1) the Verbal Participation Radars, 2) the Touch Participation radars, 3) the Map Contribution Chart, and 4) the Map Evolution Diagram. 
(2015). LATUX: An iterative workflow for designing, validating, and deploying learning analytics visualizations. Journal of Learning Analytics, 2(3), 9-39. http://dx.doi.org/10.18608/jla.2015.23.3

the group sessions. They had just the information in the low-fidelity prototype visualizations.

Instructors were able to use the visualizations to answer four out of the five questions. This demonstrated that the visualizations were promising in conveying information that could help instructors in monitoring some aspects of the collaborative situation at the tabletop even when the facilitator did not have the opportunity to observe the actions of the group in situ. This mimics real class contexts where the teacher devotes her attention to one group, with other groups working in parallel. Results showed that the visualizations provided instructors with key quantitative information about the equity of participation, the quantity of participation, and collaboration. However, they failed to provide information about the equity of intellectual contribution. Importantly, instructors indicated which aspects of the visualizations should be improved, which ones would be valuable for classroom use, and which other aspects of group work they considered important to visualize.

Main lessons learnt: In line with the UX evaluation literature (Tohidi et al., 2006), this inexpensive paperbased prototyping allowed exploration of initial user experience to drive the design of the awareness tool. For example, the evaluation described above demonstrated how instructors can identify visualizations that they predicted would be useful in class and distinguished them from others that they would prefer to use for post-hoc reflection, outside of the demands and time pressure of the actual classroom. This informed the choice of goals in the following studies and the iterative design of the awareness tool in general. Results from this evaluation also helped to refine the design of the visual aspects of the group indicators as well as to detect what other visualizations would be useful to explore.

\subsubsection{Stage 3 - Simulations with real instructors}

Description of the study: Building on the results of the evaluation of low-fidelity prototypes described above, in this study, a high-fidelity prototype of a dashboard was built. Four instructors, all experienced in using collaborative classroom activities, were involved in the early stages of the dashboard prototype design. The design process consisted of a series of interviews, design of preliminary versions of the dashboards, and empirical evaluations of both the visualizations in the dashboard and the user interface layout. The result was a dashboard designed to enable instructors to gain awareness of group learning processes, to help them determine whether groups or individual learners needed attention. The interface showed four key facets of group work: 1) symmetry of activity, 2) degree of interaction with others' contributions, 3 ) level of collaboration, and 4) overall progress of the task. This information was displayed at two levels of detail: 1) the class level, which showed minimal information about multiple groups at the same time (with three visualizations per group); and 2) the detailed group level (based on Shneiderman, Borkowski, Alavi, \& Norman, 1998), which allowed instructors to drill down to more specific information about a select group when required (with five visualizations in a timeline; see Figure

3 , right). Eight visualizations were generated and distributed on the two different user interfaces. More details of the study can be found in Martinez-Maldonado et al. (2012). 
(2015). LATUX: An iterative workflow for designing, validating, and deploying learning analytics visualizations. Journal of Learning Analytics, 2(3), 9-39. http://dx.doi.org/10.18608/jla.2015.23.3

Evaluation: This study evaluated how instructors used the dashboard to intervene in a group and what visualizations were most effective in conveying key information to inform their decisions. Controlled studies were conducted in a lab with real data simulating classroom sessions. Student data captured from four lab sessions, with university students in groups of three, were used in the simulations. Eight simulated sessions were run with eight instructors (all different from the previous evaluation stage) to evaluate the dashboard prototype. The high-fidelity prototype simulated the real-time generation of data for each instructor, as if he or she was concurrently monitoring up to three groups for 30 minutes (as in a classroom situation). The evaluation recreated the classroom orchestration loop documented by Dillenbourg et al. (2011), where instructors monitor the classroom (at the class level of the dashboard), compare it to some desirable state, and intervene to adapt the teaching (selecting the key visualizations that helped in the decision making process and drilling down to the detailed group level of the dashboard). If the instructors decided to intervene, they had to wait at least two minutes in the detailed group level simulating the time taken to talk with that group. Instructors followed this loop throughout the duration of the trials. Data captured from the instructors' use of the dashboard, a questionnaire, and interviews were used to understand the instructors' experience with the tool. Additionally, similar to the evaluation of low-fidelity prototypes described earlier, video recordings of each group's collaboration was manually analyzed by an external observer.

Evaluation results revealed that the prototype effectively enabled instructors to identify which groups encountered problems during the group work. This indicated that providing our key quantitative indicators of group work was helpful; teachers were able to decide which group needed their attention and to provide timely feedback. The class level of the dashboard provided information from the beginning of the activity and was used as a decision making tool to help teachers manage their attention and interventions. The detailed group level, which showed chronological information, was considered only to be effective for assessing task progress after class. Additionally, our participants indicated that those visualizations providing less processed data were more effective for the management of their attention and intervention. By contrast, they saw less value in the visualizations generated using more sophisticated data processing (a graph showing overall level of collaboration as detected by a data-
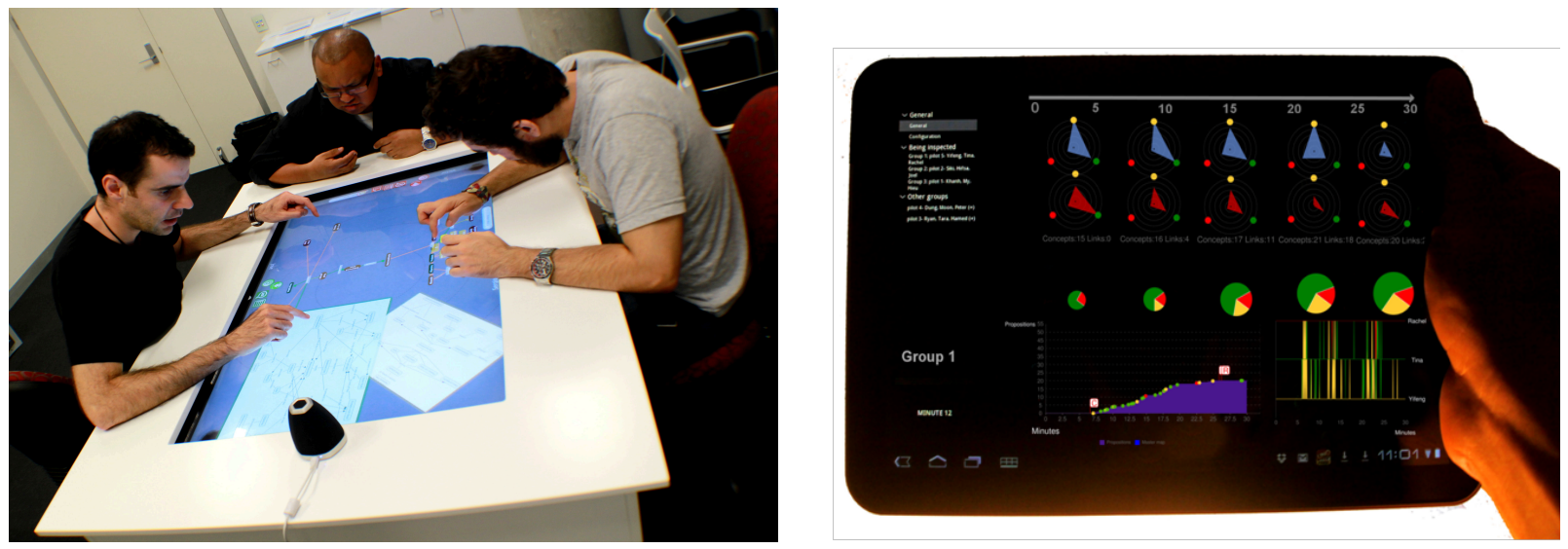

Figure 3. Simulation of a classroom using real student data: Left: a three-member group acomplishing a collaborative learning task in the lab; Right: a high-fidelity prototype of an instructor dashboard to be used by instructors in the lab. 
(2015). LATUX: An iterative workflow for designing, validating, and deploying learning analytics visualizations. Journal of Learning Analytics, 2(3), 9-39. http://dx.doi.org/10.18608/jla.2015.23.3

mining algorithm).

Main lessons learnt: Even though the construction of a programmed simulator is a more expensive task, it provided a more realistic user experience than static paper-based prototypes (Hartson \& Pyla, 2012). It meant that we could design a study where the instructors could experience a role-play, where they played a teacher who was using the visualizations and analyzing student data on the fly, as they would do in a real classroom. This helped them consider if they would realistically use the awareness tool in the classroom. For example, in this study instructors were able to identify the key features that gave them clues indicating groups with collaboration problems. Additionally, evaluating a prototype with two different levels of detail of student data provided design insights about the kind of information that should or should not be delivered to instructors in class. Providing more detailed information to instructors should be considered for cases where they want to do a careful post-mortem analysis in order to understand specific aspects of the collaboration or the learning processes.

\subsubsection{Stage 4 - Pilot studies}

Description of the study: The effectiveness of the implementation of the dashboard prototype in the classroom was validated in two consecutive semesters of authentic university level tutorials. These two pilot studies were conducted in two different weeks for two courses (at a Business school) with a single instructor conducting 22 classroom sessions (14 and 8 sessions with 236 and 140 students in each, respectively). Similar to the setting shown in Figure 4 (left), the classroom featured four interconnected interactive tabletops, each logging student actions to a central repository. All tabletops were enhanced with our CollAid system to identify students who touched the interactive surface, based on overhead depth sensors as described above. The instructor was provided with a handheld tablet, with a new version of the dashboard prototype (see Figure 4, right). This showed two real-time selected visualizations of 1) group task progress (the quality of students' work), or 2) equity of student participation (an indicator of group work), within each group. While the design of these visualizations built on lessons from the previous lab studies, we used it to create new visualizations of the information that the teacher wanted.
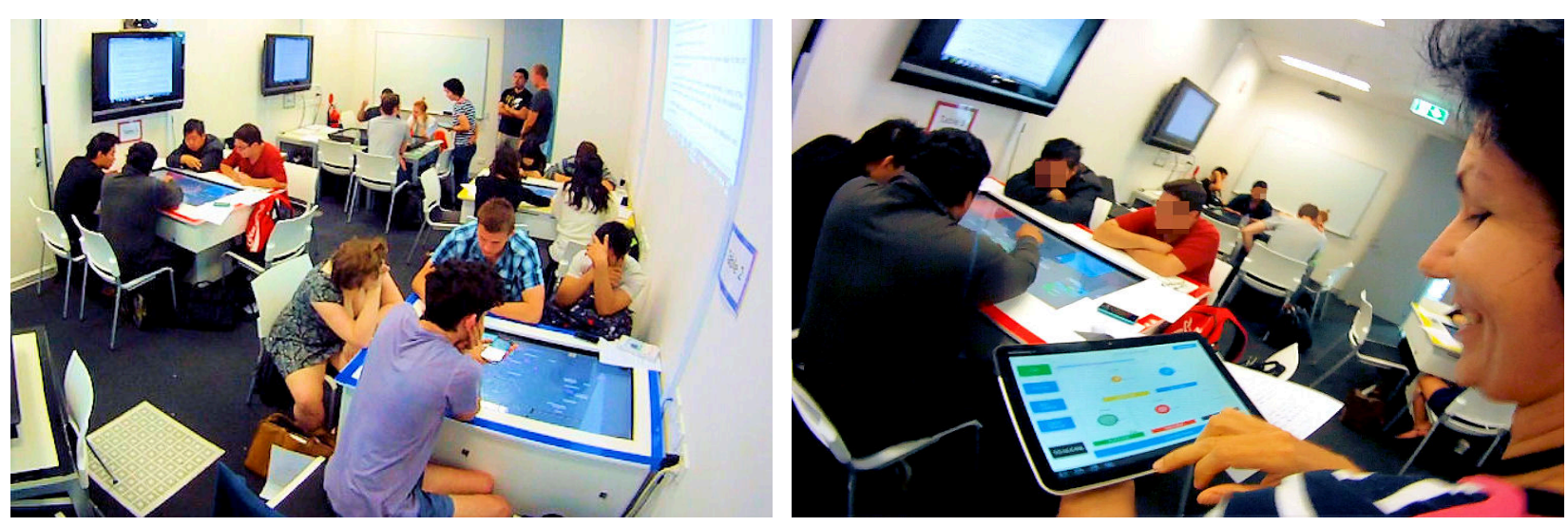

Figure 4. Pilot studies - studies in the wild: Left: a high-fidelity prototype of an instructor dashboard; and Right: an instructor using an awareness tool in-class. 
(2015). LATUX: An iterative workflow for designing, validating, and deploying learning analytics visualizations. Journal of Learning Analytics, 2(3), 9-39. http://dx.doi.org/10.18608/jla.2015.23.3

Evaluation: Learning tasks were designed by the teacher to fit into one fifty-minute weekly tutorial class in each course. The class sessions involved small-group discussions of a previously defined case study and the task required students to represent their group solutions to the posed case visually by building a concept map. During classes, the teacher moved freely among the tabletops, reviewing each group's concept map, identifying groups that needed help, and providing feedback accordingly. To evaluate the impact of the tool in the classroom, we collected information from a number of sources to triangulate evidence. These sources included application logs with user information, snapshots of the evolution of each group's concept map solution, the actions performed by the instructor on the orchestration tool and attending to groups, and notes from a second external observer whose task was to assess each small group's work at regular intervals. The evaluation focused on investigating if the instructor attended to the "lower achieving" groups, based on the information provided on the dashboard, and then if this intervention had some effect on student learning or on their task. Further details of this evaluation process can be found in Martinez-Maldonado et al. (2013) and Martinez-Maldonado (2014).

Main lessons learnt: Results showed that the data presented to the teacher in the classroom could direct their attention, especially when information about the quality of student work is delivered. By contrast, the study also confirmed that the teacher did value indicators of group work and individual participation, but mostly for post-hoc analysis. This study made evident how important it is to evaluate the tools in a real classroom environment. In the actual class, the instructor had to cope with many constraints (e.g., time limits, answering student questions, aligning with the curriculum, students arriving late, organizing the activity, and orchestrating the whole class). In addition, our provision of the awareness tool added complexity to the already multifaceted instruction activity. This study also proved that an instructor could benefit greatly from having quick access to information that is not normally easy to access in class time; for example, aspects of the quality of students' evolving solutions. The realism of this study made it difficult to test experimental conditions (e.g., alternating visualizations in the awareness tools or comparing the usage of the tool with not using it at all) due to practical or ethical issues and the teacher's wishes (e.g., she wanted all students to have similar opportunities for learning). Additionally, the evaluation in these pilot studies allowed testing the impact of the actual use of the awareness tool, going beyond simple usability to pedagogic and learning aspects. This was not possible in the previous two lab studies.

\subsubsection{Stage 5 - Classroom use}

Description of the study: Finally, the awareness tool that was iteratively built and evaluated in the lab and in pilot studies was deployed in long-term classroom studies. This deployment consisted of a longitudinal class experience running across two full university (semester) courses with four instructors (all different from those in the previous evaluation stages). The classroom experience involved 145 students. The multi-touch classroom ecology was used for the majority of the one-hour weekly tutorials for the two courses. The first was an undergraduate course on Human-Computer Interaction that had 105 students enrolled distributed in six tutorial classes taught by three instructors. The second was a postgraduate course on Pervasive Computing that had 40 students enrolled divided in two tutorial 
(2015). LATUX: An iterative workflow for designing, validating, and deploying learning analytics visualizations. Journal of Learning Analytics, 2(3), 9-39. http://dx.doi.org/10.18608/jla.2015.23.3

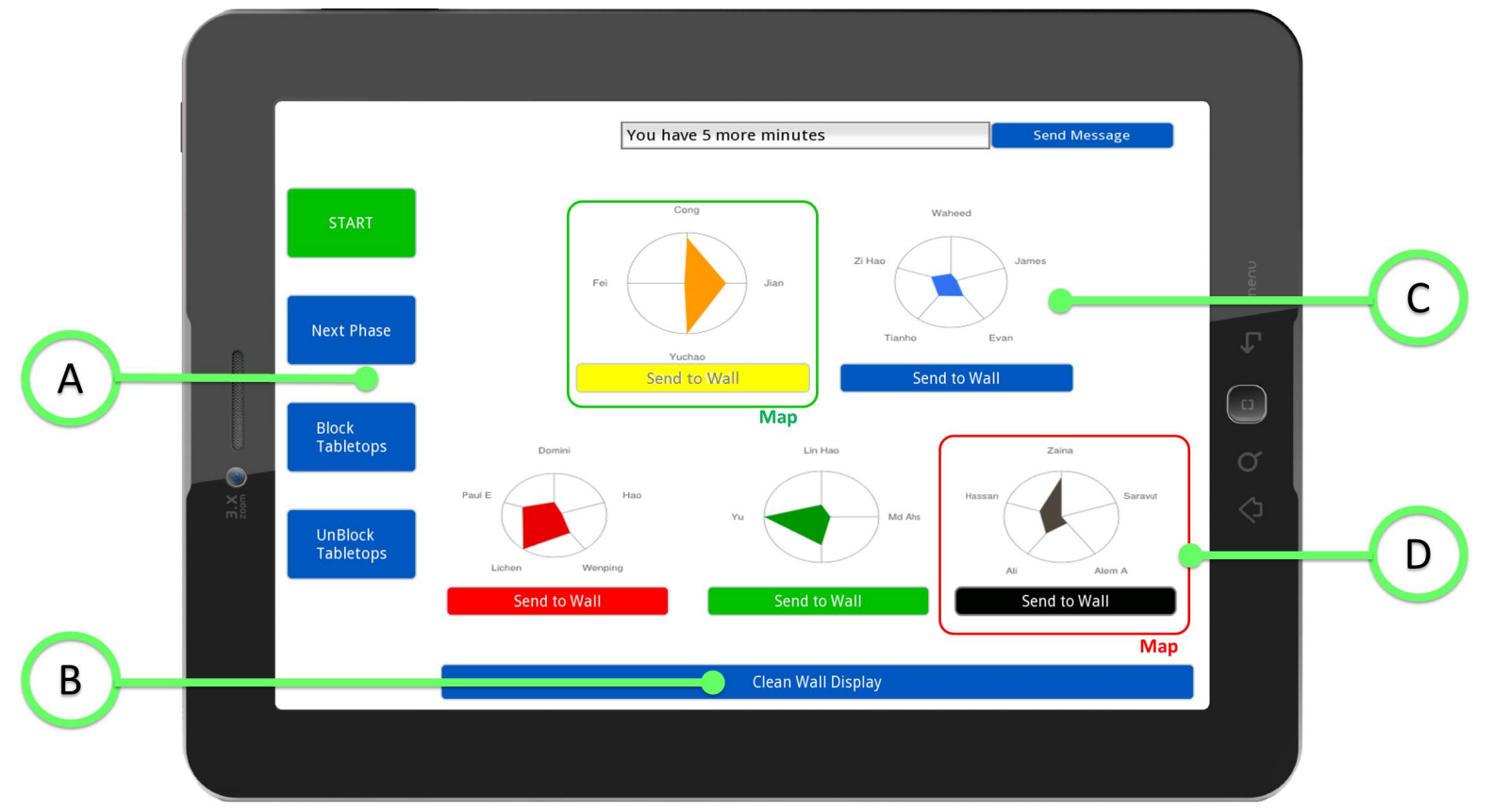

Figure 5. One final deployed teacher's dashboard featuring A) functions to control the tabletops; B) functions to control the vertical 'wall' displays; C) small group visualizations; and D) notifications

classes taught by two tutors. In this study, a full version of the awareness tool was provided. Figure 5 shows an example screen. The interface provided functions for the instructor to control the tabletops and vertical displays in the classroom (Figure 5-A and 5-B). For example, to block all the tabletops so the instructor could give instructions to the students, to move all the tabletops to a different phase of the class task, or to send the content of a specific tabletop to be displayed on a classroom vertical "wall" display. It also showed one visualization per group (Figure 5-C) and it included the provision of notifications (squares with rounded corners around visualizations - Figure 5-D) that were automatically triggered when misconceptions were detected or when groups achieved at least $50 \%$ of the task as the instructor had pre-defined it. The misconceptions were detected by comparing the runtime of each group's concept map with a list of common misconceptions defined by the teacher in design time. The dashboard reflected the change in student behaviour or the interventions performed by the instructor. For example, if the instructor attended to a group that had a misconception, the dashboard updated in runtime when (and if) the group had addressed that misconception.

Evaluation: Similar to the previous study, testing the awareness tool in-the-wild provided understanding of the impact of the tool on learning and instruction. However, a full semester deployment shed light on additional requirements for a truly useful teacher's dashboard. First, each week, the classroom sessions were different and instructors had to follow a particular script. Then, the notion of a script and a visualization portraying its enactment in real time were introduced. The group visualizations had to be generated in this context, matching the stage of the script where the class was up to, at any given time. Moreover, it was important for instructors to switch the active learning applications on the tabletops easily. Thus, the visualizations had to convey meaningful indicators of group work for different types of 
tasks supported by three different tabletop applications (in our case: concept mapping, brainstorming, and group meetings). Each of these learning applications was used at least twice during the semester in each course. Results showed how the different instructors used the visualizations according to their previous teaching experience, personal styles and each particular task each week during the courses. In some weeks the dashboard was more crucial, especially in those tasks where particular teaching goals had to be accomplished (e.g., when equal contributions from each group member were expected or when instructors had to revise knowledge of particular topics). By contrast, for more open tasks such as team meetings, the workload of regulating the class sessions was more distributed among students; hence, the instructors did not have to monitor task progress or group achievement explicitly.

Main lessons learnt: The evaluation of the awareness tool in-the-wild in this larger study gave insights about a higher degree of generalization of the results (Brown, Reeves, \& Sherwood, 2011). As in any design task, the visualizations in the dashboard are not necessarily final. However, the LATUX processes demonstrated that they are useful and meaningful. This held true for more than just the concept mapping activity, to include other learning activities as well (brainstorming and face-to-face meetings and coordination of a major multi-week project). Additionally, the in-the-wild study allowed for testing the tool with more instructors than the pilot studies and for a longer time, thus minimizing the novelty effect.

\subsubsection{Iterative Design}

The design of effective awareness tools, similar to other user interfaces, calls for an iterative process. The purpose of this case study is not to recommend all the details of these visualizations and dashboards themselves. For this there has been nascent but extensive work (Verbert et al., 2013). Rather, we used it to illustrate the process of designing and refining visual awareness tools that may be effective for a specific context. For example, Figure 6 shows the evolution of two visualizations that

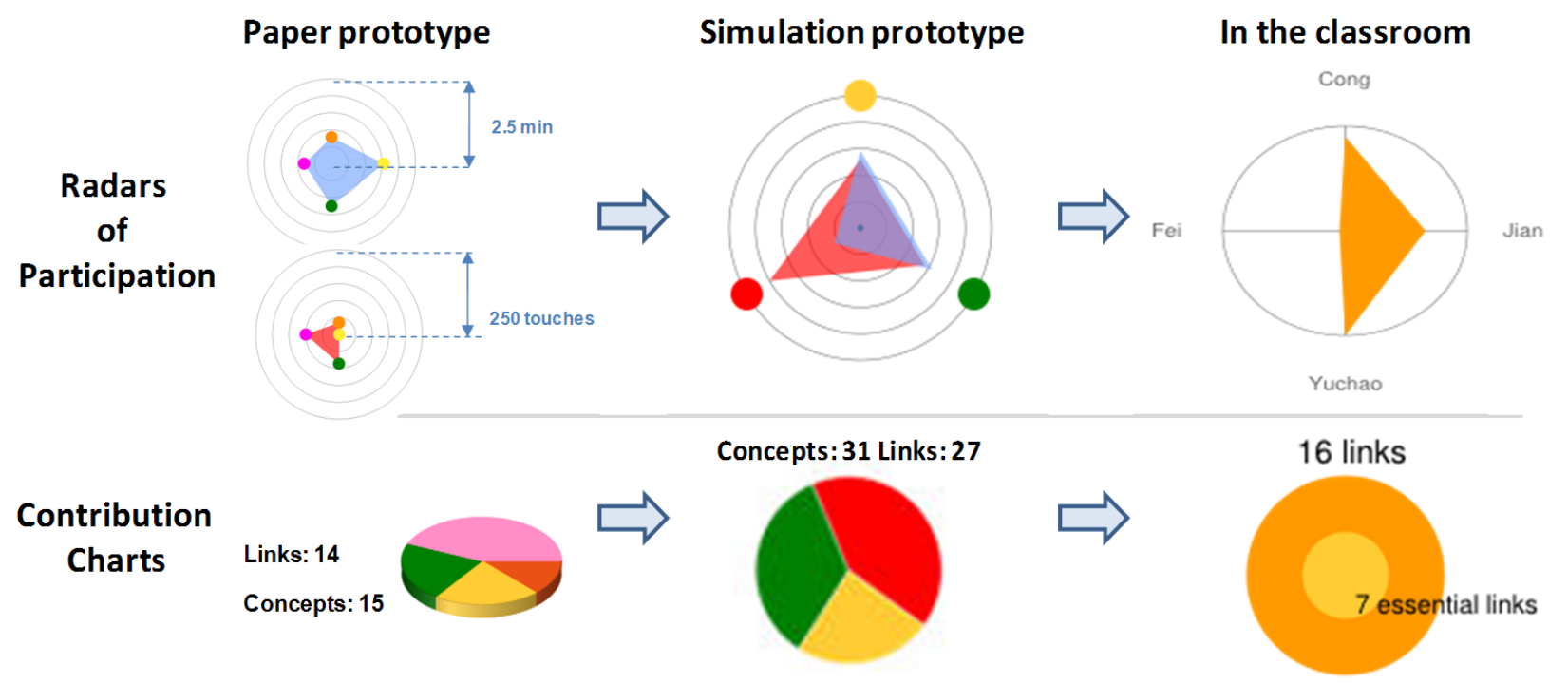

Figure 6. Evolution of two visualizations, from prototypes to deployment A) Radars of Participation and B) Contribution charts. 
(2015). LATUX: An iterative workflow for designing, validating, and deploying learning analytics visualizations. Journal of Learning Analytics, 2(3), 9-39. http://dx.doi.org/10.18608/jla.2015.23.3

were deployed in a classroom and were initially evaluated with prototypes. Although simple, they provide useful information to the instructor. It can be observed that:

1. There was a tendency towards minimalism. For example, for the visualizations "radars of participation" (see the three visualizations shown in Figure 6, top row) the first prototypes had two triangles depicting equity of verbal (blue) and touch (red) participation with the interactive tabletops. In the classroom, given the challenges for capturing clean speech data, the visualization had to be simplified to show just touch activity data from the tabletops and names of students rather than symbolic representations (coloured circles). This observation is partly in line with the data-ink ratio principle (Tufte, 1983). This principle promotes the avoidance of distracting elements as part of the visualizations design, which could be observed as the two visualizations evolved in each iteration. The principle also promotes the non-redundant display of data-information, which could be observed in the evolution of the radars of participation. However, some redundancy remained in the last design of the contribution charts (e.g., the number of links represented both as a number and as a coloured area).

2. Additionally, there was an increased focus on higher-level indicators and less on accountability. For example, for the "contribution charts" (see the three visualizations shown in Figure 6, bottom row), the pie chart used for the prototypes was simplified to indicate the size of the solution (outer orange circle, in the rightmost visualization) and the portion that matched essential elements expected by the instructor (the inner yellow circle) instead of individual contributions depicted by the slices of the pie chart.

This project is continuing to explore other visualizations of group activity that can be useful to instructors or students. Therefore, it is important to have an iterative perspective from the beginning of the design process though to the end.

\section{CONCLUSIONS AND RESEARCH AGENDA}

The design of effective LA tools requires the convergence of methodologies from multiple disciplines such as software engineering, human-computer interaction, and education. Even though these disciplines provide guidelines and frameworks to guide designers towards effective designs and systems, the LA community may benefit from paradigms that reflect its additional and specific multidisciplinary needs. There is a need for systematic processes to tackle the critical challenge of designing effective interfaces for LA applications. Our work set out to tackle the recognized need for a principled approach for designing the interfaces of LA tools. In this paper, we have reported the tabletop case studies to illustrate how to use the LATUX workflow. The series of case studies also demonstrate that the process resulted in valuable LA interfaces for learning and teaching with interactive tabletops. Figure 1 provided an overview of the five stages of the workflow, with questions for the LA tool designer to consider. The LATUX workflow calls for an iterative process, with five stages that build towards the objective of producing robust tools suitable for large-scale adoption, and based on the combination of wellestablished techniques to improve user experience while maintaining an explicit connection with the underpinning learning environment. Our LATUX workflow draws on the substantial body of work from 
(2015). LATUX: An iterative workflow for designing, validating, and deploying learning analytics visualizations. Journal of Learning Analytics, 2(3), 9-39. http://dx.doi.org/10.18608/jla.2015.23.3

SE and UX disciplines but also considers the pedagogical requirements and challenges of designing LA tools to support teaching and learning in technology-enabled learning environments. We now discuss the key lessons for using the LATUX workflow.

The reader may be concerned about the amount of effort involved in our series of studies to provide LA tools for tabletop classrooms. However, this is largely due the significant effort needed to work with very untried learning technology. We wanted to harness the digital footprints from students' touch of the tabletops and the recorded audio of their conversations. This meant that we tackled the process from a very fundamental starting point: the development of the data collection technology. For many valuable uses of LA, there are established, well understood data sources. For such data sources (e.g., data captured from the learning management system or video technologies), we expect that the progress from low-fidelity to high-fidelity prototypes and on to pilot and classroom studies can be done with modest effort. As we assemble more case studies of evaluated LA tools, we can expect to create ever-more successful LA interfaces with fewer iterations.

In our work, a key challenge was to consider the LA goals at the same time as the design of the learning activities. This was valuable, as it demanded careful thought, decision-making, and documentation of the learning objectives. Initially, we set out to provide LA tools for visualizing group collaboration. When we moved to the classroom, the topic-level learning outcomes had to be incorporated. In many widely used learning platforms, we still need to build a larger set of case studies for the Problem Identification stage. Notably, it is likely to be valuable to improve the primitives for linking learning outcomes to the available data. We then need case studies that move through the other four stages. The LATUX workflow has a role to play in supporting this exploration. In the long term, we expect that a set of core classes of requirements will emerge. For example, many online learning tools could usefully provide LA tools that show student progress in the set learning objectives. This is similar to our tool showing progress in creating the teacher's target elements in the concept maps, as well as anticipated misconceptions.

We emphasize that our contribution is the process. In addition, the series of case studies discussed represent a valuable foundation for creating tools for teachers to use for classrooms that involved small group learning activities where data is available about individual contributions and about the progress of the group task. These findings are likely to be useful for other contexts that share the same goal of enabling a teacher to see the progress of multiple small groups and to decide how to direct her attention to groups that most require it. This may also be useful for online collaborative learning activities, with multiple small groups and set class times.

The LATUX workflow has been supported with a series of case studies on the development of an awareness tool for instructors to observe small group interactions in a classroom. Even though the studies discussed involve rather leading-edge technology (e.g., interactive tabletops), the core lessons learnt, and the proposed workflow have broader applicability to both existing and future learning 
technology. Further work is needed to validate the application of the workflow in blended and online learning environments, and explore cases where awareness tools are given to students or other stakeholders. Future work is also needed on aligning the LA solutions with the design of the learning activities (including the configuration of tools, tasks, and pedagogical strategies) to support instructors more effectively. We believe that this work is an initial step towards much needed research to provide methodologies for the design of LA awareness tools. We consider the area of design frameworks as a crucial aspect to contribute to the holistic view of LA, foster its widespread adoption, and improve the overall learning and teaching experience.

\section{ACKNOWLEDGEMENTS}

This research was supported by funding from the Faculty of Engineering \& Information Technologies, The University of Sydney, under the Faculty Research Cluster Program.

\section{REFERENCES}

Arnold, K. E., \& Pistilli, M. D. (2012). Course signals at Purdue: Using learning analytics to increase student success. Proceedings of the $2^{\text {nd }}$ International Conference on Learning Analytics and Knowledge (LAK'12), 267-270. http://dx.doi.org/10.1145/2330601.2330666

Bachour, K., Kaplan, F., \& Dillenbourg, P. (2010). An interactive table for supporting participation balance in face-to-face collaborative learning. IEEE Transactions on Learning Technologies, 3(3), 203213. http://dx.doi.org/10.1109/TLT.2010.18

Bakharia, A., \& Dawson, S. (2015). Using sentence compression to develop visual analytics for student responses to short question answers. In E. Duval, K. Verbert, J. Klerkx, M. Wolpers, A. Pardo, S. Govaerts, ... D. Parra, (Eds.), Proceedings of the First International Workshop on Visual Aspects of Learning Analytics (VISLA '15) (pp.11-13). Poughkeepsie, NY, USA: CEUR-WS.org. Retrieved from http://ceur-ws.org/Vol-1518/paper2.pdf

Balacheff, N., \& Lund, K. (2013). Multidisciplinarity vs. multivocality, the case of "learning analytics." Proceedings of the $3^{\text {rd }}$ International Conference on Learning Analytics and Knowledge (LAK '13), 5-13. http://dx.doi.org/10.1145/2460296.2460299

Beer, C., Jones, D., \& Clark, D. (2012). Analytics and complexity: Learning and leading for the future. In M. Brown, M. Hartnett, T. Stewart (Eds.), Proceedings of the $29^{\text {th }}$ Annual Conference of the Australasian Society for Computers in Learning in Tertiary Education (ASCILITE 2012): Future Challenges, Sustainable Futures, 25-28 October 2012, Wellington, New Zealand (pp. 78-87).

Bevan, N. (2009). International standards for usability should be more widely used. Journal of Usability Studies, 4(3), 106-113.

Bienkowski, M., Feng, M., \& Means, B. (2012). Enhancing teaching and learning through educational data mining and learning analytics: An issue brief. Washington, DC: US Department of Education, Office of Educational Technology. Retrieved from https://tech.ed.gov/wpcontent/uploads/2014/03/edm-la-brief.pdf 
(2015). LATUX: An iterative workflow for designing, validating, and deploying learning analytics visualizations. Journal of Learning Analytics, 2(3), 9-39. http://dx.doi.org/10.18608/jla.2015.23.3

Blikstein, P. (2013). Multimodal learning analytics. Proceedings of the $3^{\text {rd }}$ International Conference on Learning Analytics and Knowledge (LAK '13), 102-106. http://dx.doi.org/10.1145/2460296.2460316

Brown, B., Reeves, S., \& Sherwood, S. (2011). Into the wild: Challenges and opportunities for field trial methods. Proceedings of the SIGCHI Conference on Human Factors in Computing Systems (CHI '11), 1657-1666. http://dx.doi.org/10.1145/1978942.1979185

Bull, S., \& Kay, J. (2007). Student models that invite the learner in: The SMILI open learner modelling framework. International Journal of Artificial Intelligence in Education, 17(2), 89-120.

Campbell, J. P., DeBlois, P. B., \& Oblinger, D. G. (2007). Academic analytics: A new tool for a new era. Educause Review, 42(4), 40. Retrieved from http://er.educause.edu/articles/2007/7/academicanalytics-a-new-tool-for-a-new-era

Chaka, C. (2010). Collaborative learning: Leveraging concept mapping and cognitive flexibility theory. In P. L. Torres \& R. d. C. V. Marriott (Eds.), Handbook of research on collaborative learning using concept mapping (pp. 152-170). Birmingham, UK: Idea Group.

Charleer, S., Klerkx, J., \& Duval, E (2015). Exploring inquiry-based learning analytics through interactive surfaces. In E. Duval, K. Verbert, J. Klerkx, M. Wolpers, A. Pardo, S. Govaerts, ... D. Parra, (Eds.), Proceedings of the First International Workshop on Visual Aspects of Learning Analytics (VISLA '15) (pp.32-35). Poughkeepsie, NY, USA: CEUR-WS.org. Retrieved from http://ceur-ws.org/Vol1518/paper6.pdf

Chatti, M. A., Dyckhoff, A. L., Schroeder, U., \& Thüs, H. (2012). A reference model for learning analytics. International Journal of Technology Enhanced Learning, 4(5), 318-331. http://dx.doi.org/10.1504/IJTEL.2012.051815

Clayphan, A., Kay, J., \& Weinberger, A. (2013). Scriptstorm: Scripting to enhance tabletop brainstorming. Personal and Ubiquitous Computing, 18(6), 1433-1453. http://dx.doi.org/10.1007/s00779-013$\underline{0746-z}$

Clayphan, A., Martinez-Maldonado, R., Ackad, C., \& Kay, J. (2013). An approach for designing and evaluating a plug-in vision-based tabletop touch identification system. Proceedings of the 25th Australian Computer-Human Interaction Conference: Augmentation, Application, Innovation, Collaboration (OzCHI '13), 467-476. http://dx.doi.org/10.1145/2541016.2541019

Dahlbäck, N., Jönsson, A., \& Ahrenberg, L. (1993). Wizard of Oz studies: Why and how. Proceedings of the International Conference on Intelligent User Interfaces (IUI 1993), 193-200. http://dx.doi.org/10.1145/169891.169968

Dillenbourg, P., Zufferey, G., Alavi, H., Jermann, P., Do-Lenh, S., Bonnard, Q., Cuendet, S., \& Kaplan, F. (2011). Classroom orchestration: The third circle of usability. In H. Spada, G. Stahl, N. Miyake, \& N. Law (Eds.). Connecting computer-supported collaborative learning to policy and practice: CSCL 2011 conference proceedings (Vol. 1), (pp. 510-17). Lulu:ISLS

Duval, E. (2011). Attention please! Learning analytics for visualization and recommendation. Proceedings of the $1^{\text {st }}$ International Conference on Learning Analytics and Knowledge (LAK '11), 9-17. http://dx.doi.org/10.1145/2090116.2090118

Duval, E., Verbert, K., Klerkx, J., Wolpers, M., Pardo, A., Govaerts, S., Gillet, D., ... Parra, D. (2015). 
(2015). LATUX: An iterative workflow for designing, validating, and deploying learning analytics visualizations. Journal of Learning Analytics, 2(3), 9-39. http://dx.doi.org/10.18608/jla.2015.23.3

Proceedings of the First International Workshop on Visual Aspects of Learning Analytics (VISLA '15). Poughkeepsie, NY, USA: CEUR-WS.org. Retrieved from http://ceur-ws.org/Vol-1518/

Dyckhoff, A. L., Zielke, D., Bültmann, M., Chatti, M. A., \& Schroeder, U. (2012). Design and implementation of a learning analytics toolkit for teachers. Educational Technology \& Society, 15(3), 58-76.

Erickson, T., Smith, D., Kellogg, W., Laff, M., Richards, J., \& Bradner, E. (1999). Socially translucent systems: Social proxies, persistent conversation, and the design of "babble." Proceedings of the SIGCHI Conference on Human Factors in Computing Systems (CHI '99), 72-79. http://dx.doi.org/10.1145/302979.302997

Ferguson, R. (2012a). Learning analytics: Drivers, developments and challenges. International Journal of Technology Enhanced Learning, 4(5/6), 304-317. http://dx.doi.org/10.1504/IJTEL.2012.051816

Ferguson, R. (2012b). The state of learning analytics in 2012: A review and future challenges (Technical Report KMI-12-01). Retrieved from the Knowledge Media Institute, The Open University, UK http://kmi.open.ac.uk/publications/techreport/kmi-12-01

Gluga, R., Kay, J., Lister, R., Simon, S., Charleston, M., Harland, J., \& Teague, D. M. (2013). A conceptual model for reflecting on expected learning vs. demonstrated student performance. In A. Carbone \& J. Whalley. (Eds.) Proceedings of the $15^{\text {th }}$ Australasian Computing Education Conference (ACE 2013) (pp. 77-86). Adelaide, Australia: Australian Computer Society.

Greller, W., \& Drachsler, H. (2012). Translating learning into numbers: A generic framework for learning analytics. Educational Technology \& Society, 15(3), 42-57.

Harris, A., Rick, J., Bonnett, V., Yuill, N., Fleck, R., Marshall, P., \& Rogers, Y. (2009). Around the table: Are multiple-touch surfaces better than single-touch for children's collaborative interactions? In O'Malley, C., Suthers, D., Reimann, P. \& Dimitracopolou, A. (Eds.) Proceedings of the $9^{\text {th }}$ International Conference on Computer Supported Collaborative Learning (CSCL 2009), (pp.335344). Rhodes, Greece: ISLS.

Hartson, R., \& Pyla, P. S. (2012). The UX book: Process and guidelines for ensuring a quality user experience. Elsevier.

Hecking, T., \& Hoppe, H. U. (2015). A network based approach for the visualization and analysis of collaboratively edited texts. Proceedings of the First International Workshop on Visual Aspects of Learning Analytics (VISLA '15) (pp.11-13). Poughkeepsie, NY, USA: CEUR-WS.org. Retrieved from http://ceur-ws.org/Vol-1518/paper4.pdf

Helms, J. W., Arthur, J. D., Hix, D., \& Hartson, H. R. (2006). A field study of the wheel: A usability engineering process model. Journal of Systems and Software, 79(6), 841-858. http://dx.doi.org/10.1016/j.jss.2005.08.023

ISO (2009). Ergonomics of human system interaction - Part 210: Human-centred design for interactive systems (ISO 9241-210:2010; formerly known as 13407). Geneva, Switzerland: International Organization for Standardization

Kay, J., \& Bull, S. (2015). New opportunities with open learner models and visual learning analytics. In Conati, C., Heffernan, N., Mitrovic, A., Verdejo, F. (Eds.). Artificial Intelligence in Education 
(2015). LATUX: An iterative workflow for designing, validating, and deploying learning analytics visualizations. Journal of Learning Analytics, 2(3), 9-39. http://dx.doi.org/10.18608/jla.2015.23.3

(Lecture Notes in Computer Science Series) (pp. 666-669). Berlin/Heidelberg: Springer. http://dx.doi.org/10.1007/978-3-319-19773-9_87

Knight, S., Buckingham Shum, S., \& Littleton, K. (2013). Epistemology, pedagogy, assessment and learning analytics. Proceedings of the $3^{\text {rd }}$ International Conference on Learning Analytics and Knowledge (LAK'13), 75-84. http://dx.doi.org/10.1145/2460296.2460312

Lockyer, L., Heathcote, E., \& Dawson, S. (2013). Informing pedagogical action: Aligning learning analytics with learning design. American Behavioral Scientist, 57(10), 1439-1459. http://dx.doi.org/10.1177/0002764213479367

Macfadyen, L. P., \& Dawson, S. (2010). Mining LMS data to develop an "early warning system" for educators: A proof of concept. Computers \& Education, 54(2), 588-599. http://dx.doi.org/10.1016/j.compedu.2009.09.008

Martinez-Maldonado, R. (2014). Analysing, visualising and supporting collaborative learning using interactive tabletops. (Doctoral dissertation, the University of Sydney). Retrieved from http://sydney.edu.au/engineering/it/ judy/Homec/Pubs/2014_Roberto_Martinez_Thesis_FINA L.pdf

Martinez-Maldonado, R., Clayphan, A., Ackad, C., \& Kay, J. (2014). Multi-touch technology in a higher education classroom: Lessons in-the-wild. Proceedings of the 25th Australian Computer-Human Interaction Conference: Augmentation, Application, Innovation, Collaboration (OzCHI '13), 189192. http://dx.doi.org/10.1145/2686612.2686647

Martinez-Maldonado, R., Collins, A., Kay, J., \& Yacef, K. (2011). Who did what? Who said that? Collaid: An environment for capturing traces of collaborative learning at the tabletop. Proceedings of the International Conference on Interactive Tabletops and Surfaces (ITS 2011), 172-181. http://dx.doi.org/10.1145/2076354.2076387

Martinez-Maldonado, R., Dimitriadis, Y., Kay, J., Yacef, K., \& Edbauer, M.-T. (2013). MTClassroom and MTDashboard: Supporting analysis of teacher attention in an orchestrated multi-tabletop classroom. In R. Nikol, M. Kapur, M. Nathan, S. Puntambekar (Eds.), Proceedings of the International Conference on Computer Supported Collaborative Learning (CSCL 2013) (Vol. 1), (pp. 119-128). Madison, USA:ISLS.

Martinez-Maldonado, R., Kay, J., \& Yacef, K. (2010). Collaborative concept mapping at the tabletop. Proceedings of the International Conference on Interactive Tabletops and Surfaces (ITS 2010) (pp.207-210). http://dx.doi.org/10.1145/1936652.1936690

Martinez-Maldonado, R., Kay, J., \& Yacef, K. (2011). Visualisations for longitudinal participation, contribution and progress of a collaborative task at the tabletop. In H. Spada, G. Stahl, N. Miyake, \& N. Law (Eds.). Connecting computer-supported collaborative learning to policy and practice: CSCL 2011 conference proceedings (Vol. 1), (pp. 25-32). Lulu:ISLS

Martinez-Maldonado, R., Pardo, A., Mirriahi, N., Yacef, K., Kay, J., \& Clayphan, A. (2015). The LATUX workflow: Designing and deploying awareness tools in technology-enabled learning settings. Proceedings of the $5^{\text {th }}$ International Conference on Learning Analytics and Knowledge (LAK '15), 1-10. http://dx.doi.org/10.1145/2723576.2723583 
(2015). LATUX: An iterative workflow for designing, validating, and deploying learning analytics visualizations. Journal of Learning Analytics, 2(3), 9-39. http://dx.doi.org/10.18608/jla.2015.23.3

Martinez-Maldonado, R., Yacef, K., Kay, J., \& Schwendimann, B. (2012). An interactive teacher's dashboard for monitoring multiple groups in a multi-tabletop learning environment. Proceedings of the International Conference on Intelligent Tutoring Systems (ITS 2012), 482-492. http://dx.doi.org/10.1007/978-3-642-30950-2_62

Mendiburo, M., Sulcer, B., \& Hasselbring, T. (2014). Interaction design for improved analytics. Proceedings of the $4^{\text {th }}$ International Conference on Learning Analytics and Knowledge (LAK '14), 78-82. http://dx.doi.org/10.1145/2567574.2567628

Niemann, K., Rojas, S. L., Wolpers, M., Scheffel, M., Drachsler, H., \& Specht, M. (2015). Getting a grasp on tag collections by visualising tag clusters based on higher-order co-occurrences. In E. Duval, K. Verbert, J. Klerkx, M. Wolpers, A. Pardo, S. Govaerts, ... D. Parra, (Eds.), Proceedings of the First International Workshop on Visual Aspects of Learning Analytics (VISLA '15) (pp.14-18). Poughkeepsie, NY, USA: CEUR-WS.org. Retrieved from http://ceur-ws.org/Vol-1518/paper3.pdf

Ochoa, X. (2015). Visualizing uncertainty in the prediction of academic risk. In E. Duval, K. Verbert, J. Klerkx, M. Wolpers, A. Pardo, S. Govaerts, ... D. Parra, (Eds.), Proceedings of the First International Workshop on Visual Aspects of Learning Analytics (VISLA '15) (pp.4-10). Poughkeepsie, NY, USA: CEUR-WS.org. Retrieved from http://ceur-ws.org/Vol-1518/paper1.pdf

Olmos, M., \& Corrin, L. (2012). Academic analytics in a medical curriculum: Enabling educational excellence. Australasian Journal of Educational Technology, 28(1), 1-15.

Prieto, L. P., Dlab, M. H., Gutiérrez, I., Abdulwahed, M., \& Balid, W. (2011). Orchestrating technology enhanced learning: A literature review and a conceptual framework. International Journal of Technology Enhanced Learning, 3(6), 583-598. http://dx.doi.org/10.1504/IJTEL.2011.045449

Ritsos, P. D., \& Roberts, J. C. (2014). Towards more visual analytics in learning analytics. In M. Pohl \& J. Roberts (Eds.), Proceedings of the Eurographics Conference on Visualization Workshop on Visual Analytics (EuroVis 2014). Swansea, Wales: The Eurographics Association. http://dx.doi.org/10.2312/eurova.20141147

Rodríguez Triana, M. J., Martínez Monés, A., Asensio Pérez, J. I., \& Dimitriadis, Y. (2014). Scripting and monitoring meet each other: Aligning learning analytics and learning design to support teachers in orchestrating CSCL situations. British Journal of Educational Technology, 46(2), 330-343. http://dx.doi.org/10.1111/bjet.12198

Shneiderman, B., Borkowski, E., Alavi, M., \& Norman, K. (1998). Emergent patterns of teaching/learning in electronic classrooms. Educational Technology Research and Development, 46(4), 23-42. http://dx.doi.org/10.1007/BF02299671

Siemens, G. (2012). Learning analytics: Envisioning a research discipline and a domain of practice. Proceedings of the $2^{\text {nd }}$ International Conference on Learning Analytics and Knowledge (LAK '12), 4-8. http://dx.doi.org/10.1145/2330601.2330605

Siemens, G., \& Baker, R. S. J. d. (2012). Learning analytics and educational data mining: Towards communication and collaboration. Proceedings of the $2^{\text {nd }}$ International Conference on Learning Analytics and Knowledge (LAK'12), 252-254. http://dx.doi.org/10.1145/2330601.2330661

Slade, S., \& Prinsloo, P. (2013). Learning analytics: Ethical issues and dilemmas. American Behavioral Scientist, 57(10), 1510-1529. http://dx.doi.org/ 10.1177/0002764213479366 
(2015). LATUX: An iterative workflow for designing, validating, and deploying learning analytics visualizations. Journal of Learning Analytics,

2(3), 9-39. http://dx.doi.org/10.18608/jla.2015.23.3

Sommerville, I. (2011). Software engineering (9th ed.). USA: Pearson Education, Inc.

Thomas, J. J., \& Cook, K. A. (2006). A visual analytics agenda. Computer Graphics and Applications, IEEE, 26(1), 10-13. http://dx.doi.org/10.1109/MCG.2006.5

Tohidi, M., Buxton, W., Baecker, R., \& Sellen, A. (2006). Getting the right design and the design right. Proceedings of the SIGCHI Conference on Human Factors in Computing Systems (CHI '06), 12431252. http://dx.doi.org/10.1145/1124772.1124960

Tufte, E. R. (1983). The visual display of quantitative information. Cheshire, CT: Graphics Press.

Upton, K., \& Kay, J. (2009). Narcissus: Group and individual models to support small group work. In G.-J. Houben, G. McCalla, F. Pianesi, \& M. Zancanaro (Eds.), User modeling, adaptation, and personalization (pp. 54-65). Berlin/Heidelberg: Springer. http://dx.doi.org/10.1007/978-3-642$\underline{02247-0 \_8}$

Verbert, K., Govaerts, S., Duval, E., Santos, J. L., Assche, F., Parra, G., \& Klerkx, J. (2013). Learning dashboards: An overview and future research opportunities. Personal and Ubiquitous Computing, 18(6), 1499-1514. http://dx.doi.org/10.1007/s00779-013-0751-2 